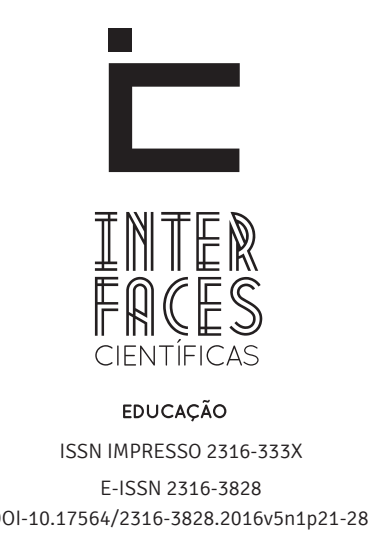

\title{
AVALIAÇ̃̃O DA APRENDIZAGEM: DO CASTIGO AO DIAGNÓSTICO PELO PROFESSOR
}

Eanes dos Santos Correia ${ }^{1}$

Arthur Cesar de Melo Tavares ${ }^{3}$
Veleida Anahi da Silva ${ }^{2}$

\section{RESUMO}

Este ensaio teórico tem o objetivo de discorrer sobre questões voltadas à avaliação da aprendizagem, a metodologia usada foi análise bibliográfica sobre os conceitos de autores que discutem a avaliação da aprendizagem e o ponto de vista de alguns deles sobre objetivos e finalidades desse processo para tomada de ação. A avaliação é usada como forma de intimidação para com os alunos, sem objetivo de aferir a aprendizagem, mas para classificação de rankings das escolas. Neste ensaio verifica-se que a avaliação deveria ser usada como possibilidade de diagnosticar as dificuldades e facilidade do processo de transmissão do saber, reorientação da aprendizagem,direcionamento para fase subsequente do processo de desenvolvimento do aluno e tomada de decisões do professor após diagnóstico. Percebe-se que a avaliação é um dos assuntos mais problemáticos e importantes quando se refere à aprendizagem. Em primeiro momento pelo fato dos professores não saberem exatamente qual o objetivo da avaliação e qual a finalidade de avaliar; Em segundo momento por utilizar a avaliação como prática de medir conhecimento e classificar alunos em dados estatísticos; e terceiro por usar a avaliação como método de castigar e disciplinar os alunos.

\section{PALAVRAS-CHAVE}

Avaliação. Ensino-Aprendizagem. Tomada de Decisão. 


\section{ABSTRACT}

The theoretical essay aims to discuss questions related to the evaluation of learning. The methodology used was literature review on the concepts of authors who discuss the assessment of learning and the views of some of them about goals and purposes of the process for making action. The assessment is used as a form of intimidation toward students without purpose of assessing learning, but for schools rankings rating. This test verifies that the assessment should be used as a possibility to diagnose difficulties and ease the transfer process of learning, reorientation of learning, guidance for subsequent stage of student development and decision-making teacher after diagnosis. It is noticed

\section{RESUMEN}

El ensayo teórico tiene como objetivo discutir cuestiones relacionadas con la evaluación del aprendizaje, la metodología utilizada fue la revisión de literatura sobre los conceptos de autores que tratan sobre la evaluación del aprendizaje y las opiniones de algunos de ellos acerca de las metas y objetivos del proceso de toma de acción. La evaluación se utiliza como una forma de intimidación hacia los estudiantes y sin propósito de evaluar el aprendizaje, sino para los niveles de clasificación de las escuelas. Este ensayo verifica que la evaluación debe ser utilizada como una posibilidad de diagnosticar las dificultades y facilitar el proceso de transferencia del aprendizaje, la reorientación de la educación, la orientación para la posterior etapa del desarrollo de los estudiantes y la toma de decisiones del profesor después del diagnóstico. Se that the assessment is one of the most problematic and important issues when it comes to learning. In the first instance by the fact that teachers do not know exactly what the objective of the evaluation and what the purpose of evaluating; Second time to use the assessment as a practice of measuring knowledge and classify students on statistical data; and third to use the assessment as a means to punish and discipline students.

\section{KEYWORDS}

Assessment. Teaching and Learning. Decision taking.

dio cuenta de que la evaluación es una de las cuestiones más problemáticas e importantes cuando se trata de aprendizaje. En el primer momento por el hecho de que los profesores no saben exactamente cuál es el objetivo de la evaluación y cuál es el propósito de la evaluación; En el segundo momento, por utilizar la evaluación como una práctica de medir el conocimiento y clasificar a los estudiantes sobre los datos estadísticos; y tercero para utilizar la evaluación como medio para castigar y disciplinar los estudiantes.

\section{PALABRAS CLAVE}

Evaluación. Enseñando y aprendiendo. Toma de decisiones. 


\section{INTRODUÇ̃̃O}

A avaliação faz parte do processo didático de qualquer instituição pública ou privada, de nível básico e superior. No processo ensino-aprendizagem a avaliação é um instrumento que serve para aferir o nível ou grau de aprendizagem do educando. É objetivo comum da avaliação, atualmente, dar notas e atribuir conceitos, mas para Mediano (2007, p. 157) “isso passa a não ser relevante. 0 que se deseja é que a avaliação seja um instrumento para levar todos a adquirirem o saber." A avaliação deve ter critérios prévios e claramente estabelecidos, mas na maioria das vezes os professores não têm critérios e quando os têm, são arbitrários. Avaliam os alunos só por cumprir um requisito do planejamento para aprovar ou reprovar.

Portanto, o que deve realmente ser avaliado é deixado de lado, pelos professores e pela escola, ignorando o real objetivo da avaliação da aprendizagem. Percebe-se que a cultura de avaliação adotada pela escola é da verificação, que classifica o aluno e não o reorienta para uma aprendizagem efetiva ou direciona para uma fase subsequente, caso seu desempenho seja satisfatório aos padrões do sistema escolar.

Em outra ótica, vê-se a avaliação como forma de controle da moral do professor na sala de aula e de intimidação para que o aluno comporte-se para não ser reprovado no final do ano letivo como castigo da sua indisciplina e não assimilação de conteúdos ditos previstos para a sua formação. Aferir, diagnosticar, classificar, verificar, castigar ou reorientar? Para que realmente serve a avaliação? 0 presente trabalho é um ensaio teórico que tem o objetivo de discutir sobre questões voltadas à avaliação da aprendizagem, mostrar conceitos de autores que discorrem a avaliação da aprendizagem e o ponto de vista de alguns deles sobre conceitos, objetivos e finalidades desse processo para tomada de ação.

\section{PANORAMA DA PRÁTICA AVALIATIVA NA ESCOLA}

A avaliação, como tarefa didática, torna-se necessária no processo de ensino e aprendizagem (LIBÂNEO, 1994). A prática dominante na escola hoje é uma prática com mecanismos de reprodução e conservação da sociedade, por meio do autoritarismo, garantindo então este modelo a avaliação não foge desse caminho autoritário (LUCKESI, 2010).

A avaliação no olhar do aluno serve para promoção de passar de ano, para o professor na maioria das vezes, como instrumento de terror e intimidação para que o aluno tenha uma postura no mínimo correta, quieta, na sala de aula mesmo que não aprenda nada, e não como um instrumento para diagnosticar o que o aluno aprendeu de acordo com o que o professor ensinou. Deve-se avaliar aquilo que ensina e aferir o que o aluno assimilou. Para os pais o mais importante é ver o filho passando de um ano para outro no final do período letivo sem se quer acompanhar a evolução da aprendizagem do seu filho. 0 que importa não é o que aprendeu, mas passar de ano.

A avaliação deve romper os seus limites de autoritarismo vigente e que esteja a serviço de uma prática de ensino com mecanismos de transformação social, transformação com quebra de latências autoritárias e conservadora, com base para um ensino como um instrumento de aprendizagem e transformação da prática social (LUCKESI, 2010).

Pode-se perceber que se a avaliação da aprendizagem é autoritária ela provavelmente está a serviço de um ensino tradicional e conservador, e quando atenta à transformação está a serviço de um ensino que se encontra preocupado e ligado à transformação da sociedade a favor do aluno como parte integrante de um todo (LUCKESI, 2010).

A avaliação deve estipular como função o diagnóstico e não a classificação. Serve como pausa para 
pensar na prática e retornar a ela, como momento de juntar "força” para voltar à marcha (ensino) mais adequada, tendo a aprendizagem como um objeto avaliativo dinâmico. Portanto, a avaliação com função classificatória serve somente para definir a aprendizagem em inferior, média ou superior, ou como forma de castigo, se tiver um baixo desempenho. Ela deve ter função diagnóstica, auxiliando no avanço e no processo de crescimento para autonomia do aluno.

Dessa forma Mediano (2007, p. 157) explicita que a finalidade classificatória da avaliação

Perde seu significado, pois não interessa classificar o aluno como fraco, carente, incompetente, mas buscar [...] diagnosticar as dificuldades do processo de transmissão, aquisição de conhecimento, buscar falhas tanto na transmissão, como na aquisição, para tomar decisões da próxima etapa do processo.

A comunicação no processo de avaliação não pode ser ambígua, com sentido duplo, ou em forma de pegadinhas só por puro prazer de fazer o aluno errar, sabendo que o mesmo detém o conhecimento e a habilidade esperada. A avaliação deve ter objetivos claros concatenados ao que os alunos estão trabalhando e os alunos devem estar cientes do que está sendo ensinado e para que está sendo avaliado (LIBÂNEO, 1994).

A avaliação classificatória domestica os alunos e a diagnóstica humaniza, serve como encaminhamento de ultrapassagem do autoritarismo da sociedade conservadora.

O Julgamento de valor das avaliações de transformação social por meio do diagnóstico que serve necessariamente para tomada de decisões relevantes da realidade. 0 professor com prática educacional transformadora age consciente, racional e reflexivamente dentro do encaminhamento da transformação social e sua precisão é clara para os encaminhamentos e realidades das suas ações.

\section{AVALIAR COMO FORMA DE CASTIGAR OU COMO POSSIBILIDADE DE UTILIZAÇÃO CONSTRUTIVA PARA TOMADA DE AÇÃO?}

Há tempos atrás o erro tinha punições físicas e até mesmo a mão à palmatória, hoje essas formas de castigar são raras ou extintas. Os castigos são mais sutis, onde o professor cria um clima de medo, tensão e ansiedade entre os alunos. Castigo que não atinge imediatamente o corpo físico do aluno, mas sua moral, sua personalidade, uma "Violência Simbólica" segundo o conceito de Bordieu (1975) em um dos seus livros A Reprodução.

Diante dessa forma de avaliar, verificar o erro do aluno, o professor não se interessa no que o aluno aprendeu, mas no que ele errou, o que não aprendeu. Um tipo de avaliação que serve para humilhar e ridicularizar o aluno "fraco", que não responde às suas perguntas, arguições e provas escritas corretamente e elogiando àqueles “fortes”, que respondem pelo menos à maioria das coisas que pergunta.

Libâneo (1994, p. 199) fala que esse tipo de avaliação tem “como recompensa aos 'bons' alunos e punição para os desinteressados ou indisciplinados. As notas se transformam em armas de intimidação e ameaça para uns e prêmios para outros”. Esses tipos de atitudes remetem a alguns conselhos postos por Comênio, o pai da didática.

Além desse tipo de castigo "Violência Simbólica" pelo erro do aluno existem também as privações como punição: não ir ao banheiro, não sair para o intervalo, ficar na diretoria da escola, lições extras para a sala de aula e para casa e até mesmo não poder lanchar. Existem também outros tipos de castigo para com os alunos: ameaça de reprovação no final do período letivo; atitude de ameaçar por repetidas vezes, onde o aluno já sofre por antecedência com medo do castigo. 
Ouvimos um dia um exemplo claro no ônibus, indo para a universidade, alguns alunos comentando com outros colegas que o professor de matemática havia feito uma prova relâmpago, pois os alunos não estavam sentados de maneira como o professor queria e porque alguns alunos saíram em grupo para o banheiro. Pode-se perceber que a avaliação, prova relâmpago, foi uma forma de punir os alunos e não de avaliar e diagnosticar o processo de aprendizagem. É percebido que o ambiente da sala de aula ao invés de um lugar de alegria, satisfação e aprendizagem, torna-se um local de tensão constante e medo (LUCKESI, 2010).

Mas o que faz gerar o castigo? Pode surgir pelo fato do aluno não aprender um conjunto ou determinado conhecimento, não ter tomado uma determinada postura diante do professor e da turma, por demonstrar apatia e desinteresse pela aula. Pensando nesta lógica o aluno deve "pagar' pelo erro ou por determinada conduta e que por meio dele, castigo por errar, aprenda como exemplo para que não ocorram eventos posteriores.

Argumenta Libâneo (1994, p. 201) que a avaliação não pode ser uma forma de castigo para os alunos "a avaliação deve ajudar [...] os ativos e os apáticos, os espertos e os lentos, os interessados e os desinteressados. Os alunos não são iguais, nem no nível sócio-econômico nem nas características individuais".

Segundo hermenêutica de Luckesi (2010) a ideia de castigo ligado ao erro ou culpa está articulado da concepção filosófica-religiosa acompanhada da cultura do ocidente cristão. Tendo como exemplo o pecado cometido por Adão e Eva e como castigo a expulsão do paraíso. A ideia de pecado e castigo atravessou épocas, carregando este sentimento até hoje. Portanto este processo não ocorre sozinho ou então somente na escola, mas se dá por meio de relações sociais no modo de agir das pessoas sobre seus sentimentos e autocontrole. Dessa forma a sociedade conservadora se mantém com autocontrole internalizado pelas pessoas, tendo a culpa como utilidade para sua permanência. Nessa compreensão o uso do erro está muito além da sala de aula, está nas relações sociais, na pele da sociedade conservadora.

O erro pode ser visto como processo de crescimento do aluno? Sim! Mas temos que considerar que não existe acerto e nem erro, mas o sucesso e o insucesso como resultado de uma atividade na busca do conhecimento, sem padrão de julgamento de certo e errado, mas com ideia de construção que pode chegar a um resultado satisfatório ou não-satisfatório. 0 acerto ou o erro, o sucesso ou insucesso, pode ser considerado importante na aprendizagem do aluno. Pode-se considerar o insucesso como um indicador de que ainda não se chegou à posição que deveria se chegar para determinada solução e também como uma forma ou modo de não mais resolver o que se pretendia solucionar ou chegar da mesma forma, podendo superá-lo como benefício significativo para o crescimento do aluno, porém o castigo não dá a possibilidade para essa reorientação não dando chances ou condições para o aluno superar o erro de forma consciente, revisando-o e avançando.

Percebe-se, então, que o erro no processo de aprendizagem não pode resultar em motivo de castigo, mas como reflexão e ponte para o avanço. A avaliação deverá servir para qualificar o aluno e ajudá-lo a alcançar realmente o que é necessário para sua formação e aprendizagem efetiva.

\section{A ESCOLA UTILIZA VERIFICAÇÃO OU AVALIAÇÃO?}

Primeiro conceituemos o que significa verificar e avaliar. Vale lembrar que verificação e avaliação estão ligadas a aprendizagem, a aferir o rendimento escolar dos alunos.

Seguindo a ótica de Luckesi (2010) a verificação significa fazer verdadeiro, ver se tal coisa ou objeto é o que pensa que deve ser e investigar tal verdade e 
comprová-la. E quando é obtida ou comprovada a informação encerra-se ali. A verificação não é dinâmica, não têm conclusões novas e significativas para si ou para o outro, somente vê se é verdade. Avaliar é dar valor a algo ou alguma coisa, esse avaliar atribui valor a um objeto de ação e não se encerra aí, provoca uma tomada de ação, a favor ou contra ele. Lembrando que o objeto de avaliação já tem um padrão previamente determinado de qualidade. Assim, ao ser atribuído valor ou qualidade conduz a duas decisões: deixar o objeto avaliado como está ou atuar sobre o objeto avaliado. Diferente da avaliação, a verificação torna-se a ação inerte, não dinâmica, já a avaliação conduz ou direciona o objeto a uma dinâmica de posições e ações em prol dela mesma.

A pesquisadora Wachowicz (2007, p. 135) também descreve o conceito de avaliar "quer dizer não valorar, ou seja, não atribuir valor ao que está sendo avaliado". Pode até entrar em divergência de conceito entre os autores, mas tem como objeto comum diagnosticar e fazer síntese de aferição do que os alunos estão aprendendo, sem nenhum julgamento, e a partir daí ter uma tomada de ação, de ação contínua. Verifica-se que o diagnóstico serve como base para uma tomada de ação, se não, seria somente verificação que classifica, reprova ou aprova e não como um aliado da aprendizagem, que encaminha e reorienta a aprendizagem, caso mostre-se insatisfatório e caso satisfatório, direcionando-a a uma fase subsequente de desenvolvimento do aluno.

Percebe-se que Luckesi (2010) confirma claramente que as escolas operam com verificação e não com a avaliação da aprendizagem. Preocupa-se em aprovar e reprovar, classificar e tornar em estatística, sem nenhum interesse no que realmente o aluno aprendeu.

Libâneo (1994, p. 198) explica que o mais comum do professor é "tomar a avaliação unicamente como ato de aplicar provas, atribuir notas e classificar os alunos. O professor usa a avaliação [...] somente como instrumento de controle". Isso mostra a que a maioria dos professores não sabe qual a finalidade real da avaliação e a utiliza somente para cumprir requisitos do planejamento e transformar em estatística de aprovação e reprovação no final do período letivo. Vê-se a utilização da avaliação como verificação e não como diagnóstico.

\section{CONCEITOS DA AVALIAÇÃO E PADRÃO MÍNIMO DE CONHECIMENTO}

Para que se possa avaliar no processo de ensino-aprendizagem o aluno deverá adquirir uma média mínima de nota estabelecida pela instituição escolar, mais especificamente, dizendo uma nota mínima estabelecida pelo sistema. Para Luckesi (2010, p. 96) “a média mínima de notas é enganosa do ponto de vista de ter ciência daquilo que o educando adquiriu".

Para ficar mais clara a citação acima serão descritos exemplos: tendo como padrão de média mínima a nota cinco, o aluno obteve nota nove em histologia vegetal, dez em citologia vegetal e dois em fisiologia animal. No final do bimestre o aluno obteve media sete das três notas acumuladas. Para quem vê a nota média final pensa que o aluno aprendeu a mais que o mínimo necessário, cinco, mas não observa que o aluno não teve um aproveitamento satisfatório em fisiologia animal, com nota dois. Revela-se que o aluno não teve aproveitamento suficiente relativo à fisiologia, mas será aprovado pela média mínima padrão do conhecimento.

É fato que a nota pela média mínima não avalia a aprendizagem efetiva dos conhecimentos mínimos necessários do aluno, mas equaliza as notas sejam elas boas ou ruins em uma, somente, sem mostrar o desempenho efetivo do aluno em cada uma delas.

Outro exemplo que pode ser citado para explicar a importância de uma avaliação como diagnóstico para reorientação da aprendizagem, caso insatisfatória e 
como direcionamento para passos subsequentes da aprendizagem, caso seja satisfatória Libâneo (1994) e Luckesi (2010). Um piloto de Parapente que tirou nota dez em decolar, dez em planar e mudar de direção e um em aterrissar ou pousar. Ele obteve nota média final sete como aproveitamento. Você voaria com ele sabendo que tirou nota um em pousar? Certamente não, pois arriscaria a sua vida. Esse mesmo cuidado deve-se ter ao avaliar o aluno, diagnosticar para reorientá-lo com referência à sua aprendizagem do conteúdo, habilidade ou ação, esperados essenciais para a formação e desenvolvimento do aluno.

O mesmo acontece em conceituar as notas das avaliações com objetivo de aferir a aprendizagem. Segundo Luckesi (2010, p. 78) “as notas são símbolos numéricos e os conceitos (péssimo, ruim, regular etc.) são símbolos verbais”. Para Libâneo (1994, p. 195) é "um padrão de desempenho e expresso em juízo de valor (muito bom, bom, satisfatório etc.) acerca do aproveitamento escolar".

No cotidiano escolar nada adianta conceituar o aluno, classificá-lo como péssimo, regular, bom e excelente e depois anotar os conceitos no diário de classe e depois nada a fazer para que ele avance se estiver péssimo ou regular, ou melhor, dizendo se sua aprendizagem está insatisfatória. Este tipo de avaliação de classificação é antidemocrática, onde não existe uma tomada de ação do professor para uma reorientação da aprendizagem, um encaminhamento para passos subseqüentes, avanço e crescimento do conhecimento do aluno, tendo como base a democratização do ensino, o acesso e a permanência do aluno na escola, não somente um acesso e permanência para ocupar uma cadeira na sala de aula, mas com ensino, aprendizagem e desenvolvimento efetivo

\section{CONSIDERAÇÕES FINAIS}

A avaliação é um dos assuntos mais problemáticos e importantes quando se refere à aprendizagem.
Em primeiro momento pelo fato dos professores não saberem exatamente qual o objetivo da avaliação e qual a finalidade de avaliar, que é a partir da avaliação que deve haver uma tomada de ação. Em segundo momento por utilizar a avaliação como prática de medir conhecimento e classificar alunos para resultado, ou seja, as notas como dados estatísticos e terceiro por usar a avaliação como método de castigar e disciplinar os alunos e utilizando-a como instrumento de poder dentro da sala de aula.

Além de utilizar como arma de poder e intimidação o processo de avaliação da aprendizagem ignora a cultura do aluno e sua origem, discrimina as reais condições do aluno, principalmente os de origens de baixa renda. Avaliar a aprendizagem é fazer uma aferição do desempenho e assimilação de conhecimentos adquiridos pelo aluno para tomadas de decisões (LUCKESI, 1978). Detectar, caso haja falha, corrigir, superá-las e fazer com que a transmissão do conhecimento realmente ocorra de forma efetiva (MEDIANO, 2005).

A avaliação ajuda como possibilidade de revisão do plano de ensino, refletir sobre a unidade objetivos-conteúdos-métodos, analisar o rendimento escolar dos alunos e refletir valores e expectativas do professor em relação ao aluno e na sua autopercepção, pois ao analisar o rendimento dos alunos obtém, conjuntamente, informações sobre o seu desenvolvimento e do próprio trabalho de ensino (LIBÂNEO, 1994). Portanto a avaliação em si é uma via de mão dupla, serve para diagnosticar o desempenho do aluno e o ensino do professor.

\section{REFERÊNCIAS}

BORDIEU, P.; PASSERON, C. A reprodução. Rio de Janeiro: Francisco Alves, 1975.

LIBÂNEO, José Carlos. Didática. São Paulo: Cortez, 1994.

LUCKESI, Cipriano. Avaliação educacional: 
pressupostos conceituais. Rio de Janeiro: Tecnologia Educacional, 1978.

\section{LUCKESI, Cipriano. Avaliação da aprendizagem} escolar. 21.ed. São Paulo: Cortez, 2010.

Recebido em: 7 de março de 2015 Avaliado em: 26 de agosto de 2015 Aceito em: 10 de agosto de 2016
MEDIANO, Zélia D. A avaliação da aprendizagem na escola de $1^{\circ} \mathrm{grau}$. In: CANDAU, V. M. (Org.). Rumo a uma nova didática. Petrópolis: Vozes, 2005.

WACHOWICZ, Lilian Anna. Avaliação e aprendizagem. In: VEIGA, Ilma P.A. (Org.). Lições de Didática. 2.ed. São Paulo: Papirus, 2007. 